\title{
Contribuições de um programa de iniciação à docência para o desenvol- vimento profissional do professor de Física
}

\author{
Luiz Marcelo Darroz ${ }^{1}$ \\ Cleci Teresinha Werner da Rosa \\ Universidade de Passo Fundo \\ Passo Fundo - RS
}

\section{Resumo}

Este texto apresenta os resultados de uma investigação realizada com egressos de um curso de formação de professores de Física sobre a importância do Programa Institucional de Bolsa de Iniciação à Docência (Pibid) para sua atuação profissional. A pesquisa, de natureza qualitativa, teve como corpus 35 egressos do curso de Física da Universidade de Passo Fundo, RS, que participaram do programa durante sua formação acadêmica. A coleta de dados ocorreu por meio de um questionário composto de sete questões abertas. A análise dos dados seguiu os procedimentos indicados pela análise de conteúdo, apresentados por Laurence Bardin (2001). Os resultados indicam que o Pibid tem contribuído de modo significativo para a formação do professor de Física da região e caracteriza-se como um programa de educação inovador nesse campo no Brasil, elevando a qualidade das ações acadêmicas nos cursos de licenciatura.

Palavras-chave: Pibid/Física; Ex-bolsistas de Iniciação à Docência; Formação de Professores.

\footnotetext{
${ }^{+}$Contributions of a teacher initiation program for the professional development of the Physics teacher

* Recebido: março de 2017.

Aceito: outubro de 2017.

1 E-mail: 1darroz@upf.br; ${ }^{2}$ E-mail: cwerner@upf.br
} 


\begin{abstract}
This paper presents the results of an investigation performed with alumni of a Physics teacher-training course regarding the importance of the Institutional Scholarship Program for Teacher Initiation (Pibid) for their professional work. The qualitative research included 35 Physics alumni from the University of Passo Fundo, RS, Brazil, who participated in the program during their education. Data was collected through a questionnaire with seven open questions. Data analysis followed the procedures indicated by the content analysis presented by Laurence Bardin (2001). The results indicated that the Pibid has significantly contributed to the training of Physics teachers of the region and it is characterized as an innovative education program in this field in Brazil, enhancing the quality of academic actions in undergraduate courses.
\end{abstract}

Keywords: Pibid/Physics; Former Teacher Initiation Fellows; Teacher Training.

\title{
I. Introdução
}

A Física é considerada uma das ciências que mais participam do desenvolvimento científico e tecnológico do mundo contemporâneo. Seus estudos têm contribuído significativamente para o avanço de diversas áreas, como, por exemplo, a Medicina, a Odontologia, a Agricultura e a Astronomia.

Dessa forma, o ensino da disciplina, no ensino médio, tem ganhado destaque e apresenta, entre outros, o objetivo de formar uma cultura científica que permita ao indivíduo a compreensão do mundo à sua volta e, consequentemente, do universo em que está inserido (BRASIL, 2002).

No entanto, de acordo com Darroz e Peréz (2011), o ensino de Física na educação básica brasileira muitas vezes é desenvolvido distante do contexto em que estudantes e professores estão inseridos. Para esses autores, o contraste entre o ideal e o real retrata um ensino que não proporciona uma aprendizagem que possibilite ao aluno aplicar no seu cotidiano os conhecimentos que obteve na escola.

Segundo Rosa et al. (2013), essas dificuldades evidenciadas no processo de ensinar e aprender Física são oriundas de diversas fontes, como a formação inicial dos professores, a estrutura física das escolas, a organização curricular e, até mesmo, o desinteresse dos estudantes. Nessa direção, Borges (2006) menciona que, no que diz respeito à metodologia desenvolvida pelos docentes nas aulas de Física da educação básica, privilegiam-se a transmissão dos saberes e o acúmulo de informações. $\mathrm{O}$ autor considera que esse fato está atrelado à formação desses professores. Para ele, 
[...] os professores de Física enfatizam demais a memorização de fatos e fórmulas, assim como a sua aplicação na resolução de exercícios de fim de capítulo, em detrimento do desenvolvimento do pensar científico. E eles não fazem isso por mero acaso, mas por estarem reproduzindo a abordagem e os métodos de ensino de Física que vivenciaram em sua formação. Reproduzem, pois, o que lhes ensinaram, tácita e inconscientemente, seus ex-professores (BORGES, 2006, p. 136).

Na tentativa de elevar a qualidade da formação inicial de professores nos cursos de licenciatura, a Coordenação de Aperfeiçoamento de Pessoal de Nível Superior (Capes) lançou, em 2007, o Programa Institucional de Bolsa de Iniciação à Docência (Pibid). Tal programa visa, sobretudo, estimular a docência pelo fomento de ações a serem desenvolvidas no âmbito das escolas públicas da educação básica por acadêmicos das licenciaturas, em conjunto com os professores dessas instituições e os docentes das universidades.

Acredita-se que a participação dos licenciandos nas atividades do Pibid completa os currículos acadêmicos, proporcionando experiências sólidas que lhes possibilitam enfrentar as exigências oriundas de uma sociedade moderna, em constante alteração e que se apresenta no ensino, auxiliando na qualificação desse processo. Confirmando o exposto, desde sua implantação, diversos trabalhos encontrados na literatura especializada apresentam os resultados positivos das ações desenvolvidas por meio do programa (MORYAMA; PASSOS; ARRUDA, 2013; JOHAN et al., 2014; FEJOLO; ARRUDA; PASSOS, 2013; DICK; DIESEL; HORN, 2015; PIRATELO; PASSOS; ARRUDA, 2014; MARMITT; BASSANI; DIESEL, 2013; SOUZA; GUALBERTO; SOUZA, 2015; DARROZ; WANNMACHER, 2015a, 2015b, 2016).

Contudo, algumas indagações sobre a eficácia do programa ainda persistem, e sobre elas se pretende discorrer neste texto: qual o percentual de egressos do Pibid/Física da Universidade de Passo Fundo (UPF) que se tornaram professores nas escolas da região? Qual o percentual dos que buscaram a qualificação profissional em nível de pós-graduação? De que forma o programa contribuiu para sua prática pedagógica e para a continuidade de seus estudos? Na opinião dos bolsistas de iniciação à docência, o Pibid auxilia a formação de professores no Brasil?

Buscando responder a essas perguntas, apresentam-se os resultados de uma pesquisa realizada junto aos egressos do curso de Física da UPF que participaram do Pibid durante sua graduação. O objetivo do estudo está em identificar a atividade profissional e/ou acadêmica exercida por esse grupo após a conclusão do curso; evidenciar suas concepções sobre as contribuições do programa para sua formação docente; e verificar se, em sua opinião, o Pibid auxilia a formação de professores de Física no Brasil.

Para tanto, o trabalho estrutura-se da seguinte forma: na próxima seção, são apresentados os objetivos do Pibid, relacionando-os às concepções de Nóvoa e Tardif acerca da for- 
mação docente; na sequência, descreve-se a metodologia desenvolvida na pesquisa; a seguir, divulgam-se os resultados alcançados; e no enceramento, expõem-se as considerações finais.

\section{Pibid e a formação de professores}

O Pibid, que "tem como finalidade fomentar a iniciação à docência, contribuindo para o aperfeiçoamento de formação de docentes em nível superior e para a melhoria da qualidade da educação básica pública brasileira" (BRASIL, 2010), foi instituído por meio da Portaria Normativa $\mathrm{MEC}^{0}$ 38, de 12 de dezembro de 2007, e apresenta os seguintes objetivos:

\footnotetext{
- Incentivar a formação de docentes em nível superior para a educação básica; - contribuir para a valorização do magistério;

- elevar a qualidade da formação inicial de professores nos cursos de licenciatura, promovendo a integração entre educação superior e educação básica;

- inserir os licenciandos no cotidiano de escolas da rede pública de educação, proporcionando-lhes oportunidades de criação e participação em experiências metodológicas, tecnológicas e práticas docentes de caráter inovador e interdisciplinar que busquem a superação de problemas identificados no processo de ensinoaprendizagem;

- incentivar escolas públicas de educação básica, mobilizando seus professores como coformadores dos futuros docentes e tornando-as protagonistas nos processos de formação inicial para o magistério; $e$

- contribuir para a articulação entre teoria e prática necessárias à formação dos docentes, elevando a qualidade das ações acadêmicas nos cursos de licenciatura" (BRASIL, 2013).
}

A inserção no programa se dá mediante edital específico da Capes, de acordo com o qual as instituições de ensino superior (IES) devem apresentar um único projeto institucional que contemple um ou mais subprojetos definidos pela área de conhecimento do curso de licenciatura. Tais projetos devem ser desenvolvidos por grupos de licenciandos, sob supervisão de professores da educação básica e orientação de professores das IES, e atender a diferentes características e dimensões da iniciação à docência, quais sejam:

\footnotetext{
- Estudo do contexto educacional envolvendo ações nos diferentes espaços escolares;

- desenvolvimento de ações que valorizem o trabalho coletivo, interdisciplinar e com intencionalidade pedagógica;

- planejamento e execução de atividades formativas;

- participação nas atividades de planejamento do projeto pedagógico da escola;

- análise do processo de ensino-aprendizagem dos conteúdos ligados ao subprojeto e, também, das diretrizes e dos currículos educacionais da educação básica;

- leitura e discussão de referenciais teóricos contemporâneos educacionais para o estudo de casos didático-pedagógicos;
} 
- cotejamento da análise de casos didático-pedagógicos com a prática e a experiência dos professores das escolas de educação básica, em articulação com seus saberes e sobre a mediação didática dos conteúdos;

- desenvolvimento, testagem, execução e avaliação de estratégias didáticopedagógicas e de instrumentos educacionais que incluam o uso de tecnologias educacionais e diferentes recursos didáticos; elaboração de ações no espaço escolar a partir do diálogo e da articulação dos membros do programa e destes com a comunidade;

- sistematização e registro das atividades desenvolvidas; e desenvolvimento de ações que estimulem a inovação, a ética profissional, a criatividade, a inventividade e a interação dos pares (BRASIL, 2013).

Para assegurar os resultados educacionais almejados, o programa concede cinco modalidades de bolsa: coordenação institucional, coordenação de área de gestão de processos educacionais, coordenação de área, supervisão e iniciação à docência. As duas primeiras são destinadas a docentes mestres ou doutores pertencentes ao quadro permanente da IES e que estejam em efetivo exercício da docência nos cursos de licenciatura. O coordenador institucional responde pela coordenação geral do Pibid perante as escolas, a IES, as secretarias de educação e a Capes. A ele cabe, entre outras tarefas, o acompanhamento das atividades previstas no projeto, a inclusão e exclusão dos bolsistas no sistema informatizado da Capes, a organização documental do projeto, a aplicação e a prestação de conta dos recursos recebidos. A função do coordenador de área de gestão de processos educacionais é apoiar o coordenador institucional e ser corresponsável pelo desenvolvimento do projeto, especialmente na articulação institucional das unidades acadêmicas e dos colegiados envolvidos, na organização de reuniões periódicas com a equipe do programa e na participação das atividades de acompanhamento e avaliação do Pibid definidas pela Capes (BRASIL, 2013).

O coordenador de área é um docente do quadro permanente da IES, graduado ou pósgraduado na área do subprojeto, e que está em efetivo exercício no ministério de aulas no curso de licenciatura do qual o subprojeto faz parte (BRASIL, 2013). A ele cabe, entre outras atribuições, garantir, acompanhar e registrar o planejamento, a organização e a execução das atividades previstas no subprojeto. Também é seu papel orientar e acompanhar a atuação dos bolsistas de iniciação à docência, trabalhando em conjunto com os supervisores das escolas envolvidas; e assegurar a capacitação dos professores supervisores nas normas e nos procedimentos do programa. Além disso, compete-lhe realizar o acompanhamento técnicopedagógico do projeto em desenvolvimento em sua área específica e proporcionar situações para inserção dos acadêmicos no ambiente escolar (BRASIL, 2013).

Aos acadêmicos matriculados nos cursos de licenciatura, com bom desempenho acadêmico e aprovados em processo seletivo realizado pelo Pibid da IES, é concedida bolsa de iniciação à docência para participar, no ambiente escolar, das atividades definidas pelo proje- 
to. Tal participação é orientada por um professor da educação básica, a quem é concedida uma bolsa de supervisão e o qual deve possuir licenciatura na área do subprojeto e experiência mínima de dois anos no magistério dessa etapa de ensino, além de estar ministrando aulas numa instituição parceira do programa. A ele compete planejar as ações juntamente com bolsistas, professores das escolas e coordenadores de área e mobilizar os acadêmicos para uma participação qualificada nas ações didáticas. Ele também deve manter a comunidade escolar informada sobre a sua atuação e as práticas desenvolvidas pelo Pibid, elaborar relatórios de acompanhamento das ações executadas pelos bolsistas, participar das atividades e dos eventos promovidos no âmbito da universidade, tornando-se o elo entre a escola e a IES (BRASIL, 2013).

A finalidade do Pibid volta-se, sobretudo, a oferecer aos licenciandos uma experiência inicial na sua formação, permitindo-lhes atuar diretamente em seu futuro campo de traba1ho. Tal objetivo vai ao encontro das concepções de Tardif (2014) e Nóvoa (2009), os quais compreendem que os futuros professores precisam estar em contato com a profissão, numa permanente articulação entre a teoria estudada no âmbito da universidade e a prática pedagógica.

Tardif (2014, p. 49) salienta que, no exercício da docência, originam-se "condicionantes relacionados a situações concretas que não são passíveis de definições acabadas e que exigem improvisação e habilidade pessoal, bem como a capacidade de enfrentar situações mais ou menos transitórias e variáveis". Nóvoa (2009), por sua vez, acredita que esses condicionantes são minimizados se a formação de professores for construída dentro da profissão. Para esse autor, a escola deve ser um espaço de formação docente capaz de possibilitar aos futuros professores situações de vivência que tenham como referência sistemática casos concretos. Por meio deles, torna-se possível proporcionar situações nas quais as experiências sejam analisadas do ponto de vista teórico e metodológico, gerando a construção de saberes necessários para a profissão docente.

Estar no ambiente escolar durante o processo de formação auxilia, segundo Tardif (2014), o desenvolvimento no futuro professor de saberes necessários para o seu exercício docente. Para ele (2014, p. 36), ao se formarem professores, os licenciandos desenvolvem um "saber plural, formado pelo amálgama, mais ou menos coerente, de saberes oriundos da formação profissional, de saberes disciplinares, curriculares e experimentais". A partir dessa ideia de pluralidade, o autor discute a possibilidade de que uma classificação coerente dos saberes docentes só existe quando associada à natureza diversa de suas origens, às diferentes fontes de sua aquisição e às relações que os professores estabelecem entre - e com - os seus saberes.

Os saberes da formação profissional são compreendidos por Tardif (2014) como o conjunto de saberes que, baseados na ciência e na erudição, são transmitidos aos professores durante o processo de formação inicial e/ou continuada. Eles também formam o rol de conhecimentos pedagógicos relacionados às técnicas e aos métodos de ensino (saber-fazer) legiti- 
mados cientificamente. Para o mesmo autor, os saberes disciplinares são os reconhecidos e identificados como pertencentes aos diferentes campos do conhecimento. São produzidos e acumulados pela sociedade ao longo da história da humanidade e administrados pela comunidade científica, de modo que o seu acesso se dá por meio das instituições educacionais.

Os saberes curriculares são os conhecimentos relacionados à forma como as instituições educacionais fazem a gestão dos conhecimentos socialmente produzidos e que devem ser transmitidos aos estudantes. Eles se apresentam, concretamente, sob a forma de programas escolares que os professores devem aprender e aplicar. Por fim, os saberes experimentais, muito ligados às ações do Pibid, resultam do próprio exercício da atividade profissional dos professores e/ou futuros professores, sendo produzidos pela vivência de situações específicas pertinentes ao espaço da escola e às relações estabelecidas com os alunos e colegas de profissão. Nesse sentido, "incorporam-se a experiências individual e coletiva sob a forma de habitus e de habilidades de saber-fazer e de saber ser" (TARDIF, 2014, p. 39). Na compreensão do autor, esse conjunto de saberes é "um constructo social produzido pela racionalidade concreta dos atores, por suas deliberações, racionalizações e motivações que constituem a fonte de seus julgamentos, escolhas e decisões" (TARDIF, 2014, p. 223). Através dessa concepção de saberes, construída socialmente, o pesquisador vislumbra a possibilidade de formar professores práticos reflexivos.

Nóvoa (2009) também observa que a formação docente precisa estar voltada para a reflexividade das ações do professor, na qual os seus saberes experienciais, curriculares e disciplinares sejam planejados e contextualizados. Conforme o autor, a formação de professores deve ter como ponto de partida o trabalho de reflexividade crítica sobre as práticas e de (re)construção permanente das ações pedagógicas, de modo que os futuros professores criem hábitos de reflexão e de autorreflexão (NÓVOA, 2009), continua Nóvoa, destacando que o processo de formação docente deve valorizar o trabalho em equipe e o exercício coletivo da profissão, reforçando a importância dos projetos coletivos da escola, mas que tenham como âncora os próprios professores, sobretudo os mais experientes e reconhecidos. Na sua concepção, a escola, como lugar de formação de professores, deve ser "um espaço da análise partilhada das práticas, enquanto rotina sistemática de acompanhamento, de supervisão e de reflexão sobre o trabalho docente" que vise à resolução dos problemas detectados no processo de ensino e à inovação da educação (NÓVOA, 2009, p. 214).

Nessa mesma direção, Tardif $(2014$, p. 52) ressalta que

É através das relações com os pares e, portanto, através do confronto entre os saberes produzidos pela experiência coletiva dos professores, que os saberes experienciais adquirem uma certa subjetividade: as certezas subjetivas devem ser, então, sistematizadas a fim de se transformarem num discurso da experiência capaz de informar ou de formar outros docentes e de fornecer uma resposta aos seus problemas. $O$ relacionamento dos jovens professores com os professores mais experientes, 
os colegas com os quais trabalhamos diariamente ou no contexto de projetos pedagógicos de duração mais longa, o treinamento e a formação de estagiários e de professores iniciantes, todas essas são situações que permitem objetivar os saberes da experiência. Em tais situações, os professores são levados a tomar consciência de seus próprios saberes experienciais, uma vez que devem transmiti-los e, portanto, objetivá-los em parte, seja para si mesmos, seja para seus colegas. Nesse sentido, o docente é não apenas um prático mas também um formador.

Frente a esse contexto, Nóvoa (2009) recomenda uma diversificação dos modelos e das práticas de formação, instituindo novas relações dos futuros professores com o saber pedagógico e científico, com vistas ao desenvolvimento da identidade profissional do futuro professor. Tardif (2014, p. 229), por seu turno, considera que a construção gradual da identidade profissional "advém da tomada de consciência em relação aos diferentes elementos que fundamentam a profissão e sua integração na situação de trabalho". No entendimento do autor, com o passar do tempo, os professores aprendem a estabelecer outras relações com esses saberes.

O domínio quanto ao seu trabalho leva, segundo Tardif (2014), a uma abertura em relação à construção de suas próprias aprendizagens, criando uma maior segurança e sentimento de estar sendo capaz de realizar suas funções. Por conseguinte, a trajetória profissional de professores compreende, além do domínio do saber-fazer, saber-como, o bem-estar pessoal do professor em fazê-lo. Nas suas palavras: "A experiência do trabalho docente exige um domínio cognitivo e instrumental da função, ela também exige uma socialização na profissão e em uma vivência profissional através da qual se constrói e se experimenta pouco a pouco uma identidade profissional" (TARDIF, 2014, p. 239).

Tais concepções fazem compreender que os saberes dos professores não constituem um conjunto definido de uma vez por todas, mas um processo de construção ao longo de uma carreira profissional. Nesse processo, "o professor aprende progressivamente a dominar seu ambiente de trabalho, ao mesmo tempo em que se insere nele e o interioriza por meio de regras de ação que se tornam parte integrante de sua consciência prática" (TARDIF, 2014, p. 14).

Pelo exposto, é possível perceber que as estruturas que sustentam o Pibid estão em consonância com os estudos de Tardif (2014) e Nóvoa (2009), uma vez que consideram que o ambiente escolar não é somente um lugar de aplicação de saberes produzidos por outros. Mais do que isso, o ambiente escolar constitui um espaço de produção, transformação e mobilização de saberes que lhe são próprios, no qual o futuro professor é o sujeito ativo de sua própria formação. Afinal, ao mesmo tempo em que vivencia a prática cotidiana do ambiente escolar, traz à tona as experiências de sua história de vida, sua afetividade e seus valores, além de construir seus saberes, que vão configurando a sua identidade profissional. 


\section{A pesquisa}

O subprojeto Pibid/Física da UPF passou a desenvolver suas atividades a partir da inserção da universidade no programa, através da Portaria Capes $n^{0} 72$, de 09 de abril de 2010. Desde então, o curso formou 54 professores de Física, dos quais 35 foram bolsistas de iniciação à docência durante sua graduação. Foi esse grupo que constituiu o corpus da pesquisa, tendo a maioria deles atuado no subprojeto Pibid/Física da UPF por quatro ou mais semestres.

A pesquisa realizada junto a esses sujeitos, buscando responder aos questionamentos apresentados inicialmente, caracteriza-se como qualitativa. De acordo com Lakatos e Marconi (2010), quando a coleta de informações é feita em ambiente natural e cada uma é analisada indutivamente, de modo que o processo e seu significado sejam a prioridade da pesquisa, esta tem como base a natureza qualitativa. Nessa metodologia, a realidade e a pesquisa conseguem se equiparar de maneira confiável, pois se considera que há uma relação entre o mundo objetivo e a subjetividade do sujeito que não tem como ser traduzida em números. Isto é, a pesquisa qualitativa não requer uso de métodos e técnicas estatísticas, pois a interpretação dos fenômenos e a atribuição de significados se dão pelo instrumento-chave: o pesquisador (LAKATOS; MARCONI, 2010). Por isso, é considerada de cunho descritivo, em que os pesquisadores tendem a fazer avaliações indutivas.

Para a realização do estudo, utilizou-se como instrumento de coleta de dados um questionário desenvolvido no Google Drive e composto de sete questões abertas, a saber:

1. Qual(is) foi(ram) sua(s) atividade(s) profissional(is) após a conclusão do curso de licenciatura em Física? Ministra aula atualmente?

2. Considera que o Pibid contribuiu para a escolha profissional respondida na questão anterior? De que forma?

3. Após a conclusão do curso de licenciatura em Física, realizou ou realiza algum curso de graduação, especialização, mestrado ou doutorado? Em caso positivo, especifique o curso e comente se o Pibid pode ter influenciado na continuidade dos estudos.

4. As vivências e as atividades desenvolvidas no Pibid foram aplicadas nas suas aulas após formado? Quais?

5. No caso de ter optado pela realização de curso(s) de pós-graduação, os trabalhos desenvolvidos nas disciplinas e/ou sua dissertação/tese tiveram relação com a vivência no Pibid? Comente.

6. Você recomenda aos licenciandos em Física a participação neste programa? Por quê?

7. Em sua opinião, quais as principais contribuições do programa para a formação de professores de Física no Brasil? Explique. 
De posse desses dados, realizaram uma "leitura flutuante" e uma exploração inicial do material. Esse procedimento de leitura de dados toma como referencial o anunciado por Laurence Bardin (2011), na perspectiva da análise de conteúdo. A opção por essa metodologia deve-se ao fato de a análise de conteúdo ser um conjunto de instrumentos de cunho metodológico em constante aperfeiçoamento, que se aplica em diferentes contextos extremamente diversificados, cuja função primordial é o desvendar crítico do que está sendo investigado (BARDIN, 2011, p. 15).

Após a leitura do material, efetuou-se a sua exploração, visando evidenciar elementos que levassem ao alcance dos objetivos elencados. Isto é, tentou-se, nessa fase, classificar e categorizar os dados para promover sua correta interpretação. Para tal, dividiram as questões em três categorias. Na primeira, denominada "Atuação profissional e acadêmica", foram arroladas as respostas às questões 1,2 e 3, e buscou-se identificar a atividade profissional dos ex-bolsistas, se esse grupo de sujeitos continuou os estudos em cursos de pós-graduação e como compreendem a participação do Pibid na tomada de decisão de ministrar aulas e/ou realizar curso(s) de pós-graduação. As questões 4 e 5 formaram a segunda categoria, chamada "Contribuições do Pibid/Física”, com as quais se averiguou se os ex-bolsistas acreditam que as ações desenvolvidas no programa contribuíram para a sua prática pedagógica e o prosseguimento dos estudos. A terceira categoria, intitulada "Avaliação do programa", constituiu-se das respostas às questões 6 e 7 e teve como objetivo perceber se os participantes concebem o Pibid como um programa que auxilia a formação de professores no Brasil.

Para Bardin (2006, p. 117), as categorias como as propostas para este estudo, em geral, são formas de pensamento e refletem a realidade e, na perspectiva da análise de conteúdo, são vistas como rubricas ou classes que agrupam determinados elementos, reunindo características comuns.

A seguir, são descritos os resultados do estudo, de forma a confrontá-los com a literatura no âmbito da formação de professores e dos objetivos do Pibid.

\section{Resultados e discussão}

Para a apresentação dos resultados e sua posterior análise, foram utilizados estratos dos escritos dos sujeitos da pesquisa, indicados pelas letras EB (referentes à expressão "exbolsista”), seguidas de um número.

\section{IV.1 Atuação profisssional e acadêmica}

As respostas avaliadas na questão 1 demonstram que a atividade profissional exercida após a conclusão do curso de licenciatura em Física por 22 dos 35 dos ex-bolsistas foi o magistério. Desses, 20 permanecem atuando como docentes em instituições de ensino fundamental, médio e/ou superior. Dentre os demais participantes, apenas um respondeu que nunca 
teve interesse em lecionar, enquanto todos os outros demonstram desejo de atuar como professores e estão esperando a oportunidade surgir.

Para aqueles que estão ministrando aulas, sua participação no Pibid/Física contribuiu decisivamente na escolha profissional. Segundo eles, o programa possibilitou vivenciar a realidade escolar, seu futuro local de atuação profissional, e os instigou a serem professores, como se pode perceber nos trechos das entrevistas transcritos no Quadro 1.

Quadro 1 - Trechos das entrevistas.

"O Pibid me ajudou a escolher ser professor, pois fez que eu conhecesse o ambiente [...] das escolas desde o começo da faculdade”. (EB11)

“a possibilidade de [...] ver de fato um pouco como é o dia a dia na sala de aula”. (EB12)

“a experiência de trabalhar [com] professores e alunos diretamente nas escolas". (EB13)

"o fato de estarmos vivenciando o dia a dia de ser professor desde os primeiros semestres da graduação". (EB14)

“conhecer melhor o funcionamento da escola e da prática pedagógica”. (EB24)

“[...] o programa pode ser considerado a hora da verdade, o acadêmico que tem a oportunidade de participar do projeto pode tirar a dúvida se a licenciatura é realmente o que ele quer, pois ele proporciona o contato com o mundo escolar de forma indireta, ou seja, sem a responsabilidade de um professor titular, e também deixa futuros professores com uma visão melhor de como proceder em sala de aula". (EB25)

Fonte: dados da pesquisa, 2017.

Para os ex-bolsistas, participar do programa durante o período de formação significou uma oportunidade para confirmar a escolha profissional e definir definitivamente a opção por ser professor. Tais elementos podem ser evidenciados nos fragmentos das entrevistas transcritos no Quadro 2.

Quadro 2 - Fragmentos das entrevistas.

"O Pibid foi importante para eu reafirmar minha escolha profissional [...], nessa etapa [de] que participei que pude ver que realmente gosto de lecionar”. (EB8)

[...] foi no Pibid que percebi que gostava e que poderia ser uma boa professora”. (EB20)

"[o Pibid foi] uma experiência de sala de aula fundamental para que eu decidisse de fato seguir a carreira docente, pois na época ainda não tinha certeza dessa escolha”. (EB35)

"o Pibid mostra como é a realidade do professor em uma escola pública, e tendo esse conhecimento torna-se mais fácil a escolha da carreira a ser levada”. (EB9)

Fonte: dados da pesquisa, 2017. 
O fato de vivenciar situações do cotidiano escolar e participar da rotina da sala de aula, segundo a concepção dos ex-bolsistas, possibilitou-lhes adquirir experiências que, muitas vezes, não são obtidas nos bancos acadêmicos, o que contribuiu na escolha profissional. Nessa perspectiva, EB6 acredita que a contribuição do programa para a docência está na

\begin{abstract}
inserção dentro da escola, antes da etapa dos estágios obrigatórios. Isso foi de extrema importância para experimentar a docência com maior profundidade. Pois o papel que o professor desempenha na escola não consiste somente em entrar na sala de aula e lecionar. É necessário compreender toda a dinâmica da escola, como questões administrativas, reuniões, conselhos de classe, planejamento, preparação interdisciplinar, etc., tópicos que dificilmente podem ser vivenciados somente nos meses em que o estágio docência é realizado, devido ao pequeno tempo dessa etapa. Dessa forma, o Pibid foi uma oportunidade de fortalecer meu desejo de ser professor.
\end{abstract}

Essa concepção é compartilhada por EB29 e EB21, ao afirmarem, respectivamente: "[o Pibid] me mostrou novas maneiras de enfrentar problemas e adversidades do nosso ensino atual, com ele pude ter mais embasamento teórico e prático”.

[o Pibid foi o responsável por me ensinar a] buscar sempre o melhor dentro da escola/sala de aula, sempre ter em mente que nós professores não somos apenas portadores de conteúdos. Que o conteúdo não basta! Precisamos também saber trabalhar com o ser humano e com o contexto em que ele vive.

Os resultados evidenciados nas duas primeiras questões do instrumento de pesquisa se assemelham aos achados nas investigações de Moryama, Passos e Arruda (2013) e de Darroz e Wannmacher (2016), realizadas, respectivamente, com um grupo de licenciandos de um curso de Ciências Biológicas e com um grupo de bolsistas de iniciação à docência dos subprojetos de Física do Pibid do Rio Grande do Sul. Assim como os estudos mencionados, a presente investigação aponta que a vivência cotidiana do ambiente escolar e de situações didáticas e/ou metodológicas ajuda o estudante na decisão de seguir ou não no magistério. Dessa forma, os dados encontrados na pesquisa vão ao encontro da concepção de Tardif (2014, p. 23) sobre a formação docente, conforme se verifica na sequência:

[...] um professor de profissão não é somente alguém que aplica conhecimentos
produzidos por outros, não é somente um agente determinado por mecanismos soci-
ais: é um ator no sentido forte do termo, isto é, um sujeito que assume sua prática a
partir dos significados que ele mesmo lhe dá, um sujeito que possui conhecimentos e
um saber-fazer provenientes de sua própria atividade e a partir dos quais ele a es-
trutura e a orienta.

No que diz respeito à continuidade nos estudos através da frequência em cursos de graduação ou pós-graduação, tema investigado na questão 3, os resultados demonstram que 
seis egressos realizaram e/ou realizam outro curso de graduação, tendo cinco deles optado por realizar outra licenciatura. Sete ex-bolsistas de iniciação à docência buscaram a qualificação docente em cursos de pós-graduação lato sensu (especializações na área do magistério) e treze frequentaram e/ou frequentam cursos de pós-graduação scricto sensu em nível de mestrado (doze relacionados com docência e um com engenharia). Ainda, segundo seus relatos, dois participantes da pesquisa, após realizarem o curso de mestrado, ingressaram no curso de doutorado e, atualmente, desenvolvem seu projeto em programa de pós-graduação relacionado à Educação.

Para os participantes, o Pibid/Física auxiliou na decisão de continuar os estudos relacionados ao magistério, tendo em vista que, durante a vivência de casos concretos do cotidiano escolar inúmeras vezes se defrontavam com situações que nem sempre conseguiam enfrentar apenas com base nos conhecimentos estudados nos bancos escolares. Isto é, os relatos demonstram que temas como interdisciplinaridade, adolescência, legislação educacional, dificuldades de aprendizagem, inclusão, metodologia por projetos e contextualização dos conceitos abordados, embora muito estudados na graduação, deixaram lacunas e precisaram ser revisados em cursos de pós-graduação. É o que se percebe no trecho da resposta de EB27:

\begin{abstract}
[...] foi no Pibid que pude perceber como é que ocorre tudo na escola. Ali que vi que não é só conteúdo que precisamos. Isso é o mais fácil. Percebi que precisamos lidar com a indisciplina de alguns adolescentes, que cada um tem uma forma de aprender, que precisamos contextualizar os conteúdos que ensinamos, que o estado exige que trabalhemos com projetos e tudo mais. Mesmo que tenhamos estudado tudo isso no curso de Física, percebi que precisava de algo a mais, então estou buscando no mestrado algumas respostas.
\end{abstract}

EB3 também salienta a necessidade de continuar estudando para enfrentar situações presentes no cotidiano do contexto escolar:

\begin{abstract}
Na universidade se estuda psicologia, didática, se simula situações que enfrentaremos na nossa profissão. Tudo muito teórico. Agora, quando chega na prática, nem tudo é igual ao que dizem os livros. Eu percebi isso ao participar do Pibid e, também, agora que estou atuando como professor. Ocorre que quando você está na universidade como aluno, você estuda como aluno. Quando você assume o papel de professor, tem que estudar como professor. Logo, a partir do Pibid e da minha atividade docente, resolvi fazer a especialização em Linguagens e Tecnologias da Educação com ênfase em Ciências. Acredito que isso possa me ajudar a ser uma professora melhor.
\end{abstract}

Conforme Nóvoa (2009), as escolas são espaços de aprendizagens docentes, nas quais os professores se apoiam e se estimulam mutuamente, e que possibilitam uma reflexão sobre a prática pedagógica e a transformação de saberes, obrigando aqueles que nela estão 
inseridos a buscar uma resposta aos seus dilemas pessoais, sociais e culturais. Nesse sentido, os resultados encontrados neste grupo de questões vão ao encontro da concepção do autor, uma vez que a maioria dos egressos do Pibid/Física da UPF atribui à sua participação no programa a escolha de continuar na profissão docente. Também se evidenciou que a maior parte deles está, atualmente, ministrando aulas e frequentando cursos de graduação ou pósgraduação, o que permite concluir que o objetivo do Pibid de auxiliar no incentivo da formação de docentes em nível superior para a educação básica está sendo alcançado.

\section{IV.2 Contribuições do Pibid/Física}

Os participantes indicam a experiência adquirida no programa e a utilização de atividades realizadas nesse espaço formativo no ministério das aulas após concluírem o curso de licenciatura em Física como os elementos do Pibid que mais auxiliaram na sua formação. Todos relatam fazer uso cotidianamente dos conhecimentos adquiridos no Pibid, a exemplo de EB10:

[...] durante o Pibid, realizamos muitas leituras, interpretamos diversos artigos, debatemos e discutimos. Tudo isso fez com que apendêssemos bastante. Assim, quando encontramos situações semelhantes ao que estudamos, temos mais segurança de saber como agir [...]. Também tem as atividades que planejamos durante os encontros na UPF e que aplicávamos nas escolas. Tudo isso aplico nas aulas que dou agora.

Dentre as metodologias e estratégias citadas pelos participantes, o desenvolvimento de atividades experimentais foi o que eles mais utilizaram, conforme relatam na continuidade: "trabalho muito com os experimentos simples que construímos com materiais de baixo custo, principalmente quando explico Hidrostática" (EB16); "tudo o que fizemos no Pibid é aproveitado de uma forma ou de outra, mas o que mais ocupo nas minhas aulas são as experiências que planejamos e aplicamos nas turmas do Pibid" (EB35); "também aprendi a construir materiais e hoje construo diversas coisas com meus alunos. Construímos desde materiais para as aulas experimentais até produtos que fazem parte de projetos interdisciplinares" (EB1).

Os participantes da pesquisa afirmam, ainda, utilizar em suas aulas as listas de exercícios, os jogos pedagógicos, os roteiros de atividades experimentais e diversas metodologias desenvolvidas, testadas e implementadas durante o período em que participaram das atividades do programa. Em pesquisas anteriores, Darroz e Wannmacher (2015a, 2015b, 2016) evidenciaram que, no decorrer da participação no Pibid, os participantes desenvolvem, organizam e executam diversas situações e metodologias de ensino que privilegiam a vivência dos bolsistas em casos concretos do ambiente escolar. Para esses autores, tal experiência proporciona a esses sujeitos a apropriação de um rol de atividades didáticas para as intervenções práticas no cotidiano escolar. Ainda, a possibilidade de continuarem utilizando os materiais desenvolvidos no âmbito do Pibid confirma as concepções de Tardif (2014) e Nóvoa (2009) 
de que a experiência de trabalho no ambiente escolar é o fundamento do saber docente. Com efeito, os saberes oriundos desse espaço são os alicerces para a prática e para a competência profissional dos professores.

A questão 5 indagava se os trabalhos desenvolvidos nas disciplinas, dissertações e/ou teses dos cursos de pós-graduação tiveram relação com a vivência no Pibid/Física. As respostas a essa pergunta demonstram que seis dos egressos que realizaram ou realizam cursos de pós-graduação escolheram seu tema de pesquisa a partir de situações vivenciadas no contexto escolar da educação básica durante o programa. Para eles, estar constantemente no ambiente escolar foi uma experiência que lhes permitiu identificar os conceitos sobre os quais os estudantes do ensino médio apresentam mais dificuldades e/ou metodologias de ensino que não atendem às especificidades dos conteúdos ministrados pelos docentes. Tal fato os instigou a buscar em cursos de mestrado profissional alternativas para minimizar as situações evidenciadas.

Os demais participantes da pesquisa que ingressaram em outros cursos de graduação ou pós-graduação após a conclusão da licenciatura em Física afirmam que, embora os estudos atuais não estejam diretamente relacionados às atividades desenvolvidas no Pibid/Física, o programa auxiliou muito no desenvolvimento de metodologias de estudo e de pesquisa. É o que evidencia a resposta de EB21:

[...] atualmente estou ingressando no doutorado. Neste curso vou dar continuidade à pesquisa do mestrado, que estabelece a relação entre a Física e o trânsito. Isso não tem relação com o que realizamos no Pibid. Mas o Pibid me ajudou muito a compreender a melhor forma de estudar e também como pesquisar. Lá no programa fazíamos muitas pesquisas sobre ensino de Física. Assim, no mestrado isso me ajudou muito. Tenho certeza que vai ajudar no doutorado também.

Tais resultados vão ao encontro da concepção de Nóvoa (2009), que acredita que estar no interior da escola durante a formação profissional possibilita aos professores analisar sistematicamente situações cotidianas da instituição e envolver-se com a pesquisa e a reflexão sobre sua prática, visando resolver os problemas inicialmente detectados.

\section{IV.3 Avaliação do programa}

A análise das respostas às questões 6 e 7 demonstra que todos os participantes da pesquisa recomendam os licenciandos em Física a participação no programa. A justificativa mais ressaltada para essa recomendação é o espaço criado pelo Pibid para estar presente no contexto escolar desde o início da graduação, como se pode perceber nas respostas transcritas a seguir: "Sim. O Pibid oferece a oportunidade de estar dentro de uma escola e de conhecer com maior profundidade, além de aprender com o contato com os alunos, saber como se por- 
tar, saber como tomar decisões frente a algumas situações" (EB21). "Sim, pois no Pibid o aluno tem um contato com o espaço de sala de aula antes mesmo de entrar em estágio curricular, e isso proporciona uma melhor visão da profissão de professor" (EB7). "Recomendo, pois o programa demonstra como é a profissão, como também abre a possibilidade de o acadêmico assimilar mais jeitos de dar aula e, ainda, serve para retirar o medo de entrar em sala de aula” (EB9). "Sim, [...] você também tem uma visão da convivência numa escola e o contato direto com os alunos" (EB12). "Recomendo pela contribuição que o programa faz a todos os licenciandos de nos levar à realidade de sala de aula, a ensinar a trabalhar em grupos, ter vivências com alunos e acima de tudo nos auxiliar na formação como professores" (EB19). "Sim. Um contato inicial com a profissão se faz necessário, sendo de grande valia tanto para o aluno que estará aprendendo quanto para a instituição que estará formando profissionais mais completos para o mercado de trabalho” (EB34).

O programa prepara os acadêmicos para gerenciar uma sala de aula, as abordagens necessárias, os tempos de aprendizagem dos alunos, etc. A participação de acadêmicos no programa acaba 'quebrando o gelo' de entrar pela primeira vez como professor em uma sala de aula. (EB22)

Com certeza. Pelo fato de que o Pibid traz a possibilidade de o licenciando ver na prática sua futura profissão, sem ter que esperar apenas pelo último semestre da faculdade para poder fazer um estágio, e também por oportunizar acesso a estudos que aprofundam os temas estudados nas disciplinas dos cursos. (EB29)

Ao recomendar a participação no programa, EB17 argumenta que, "além da experiência em sala de aula, o Pibid possibilita a participação em eventos e a publicação das atividades executadas". Observação semelhante é feita por EB22:

o Pibid permite momentos de trocas com colegas que geram diversas ideias e aumentam o conhecimento do grupo. Essas trocas ocorrem não somente entre nós, elas ocorrem também nos eventos científicos [de] que se participa durante o tempo do programa.

No mesmo sentido, mas com o acréscimo de novos elementos, EB13 afirma:

\begin{abstract}
Recomendo, por ser acompanhado de bons professores, de proporcionar uma aprendizagem global que vai além da aula rotineira e tradicional, que permite participar de diversos eventos e assim abrir os horizontes acerca da nossa futura atuação profissional e, por último, mas não menos importante, por receber bolsa e conseguir estudar sem precisar trabalhar durante o período de faculdade.
\end{abstract}

Por fim, na visão dos ex-bolsistas participantes da pesquisa, as principais contribuições do Pibid para a formação de professores de Física no Brasil são a possibilidade de relacionar a teoria estudada nos bancos escolares com a prática vivenciada no contexto escolar; a oportunidade de estudar a partir de casos concretos da realidade da escola básica; o conheci- 
mento adquirido em meio ao cotidiano de uma escola; a aquisição de um repertório de experiências didáticas e pedagógicas que orientarão a futura atuação profissional; a promoção de espaços propícios para que o futuro professor se dedique a uma reflexão mais sistemática e aprofundada sobre os fatos ocorridos em sala de aula; o desenvolvimento de uma ação que leve à análise coletiva das práticas, enquanto rotina sistemática de acompanhamento, de supervisão e de reflexão sobre o trabalho docente; e o recebimento de uma bolsa.

Todos esses elementos podem ser evidenciados nas respostas transcritas a seguir: " $E$ um programa que faz a ligação entre a universidade e a escola" (EB13). "O programa permite a aluno não só estudar teorias educacionais na graduação, mas testá-las na prática em ambientes reais (escolas)” (EB23). “Ajuda a aprimorar a formação do profissional e possibilita vivenciarmos situações reais da educação e buscar estudar a partir delas, pois sempre se está estudando e adquirindo novas técnicas de trabalho" (EB28). "O Pibid contribui para que os acadêmicos criem, testem e apliquem diversas metodologias de ensino ou de aulas práticas. Tudo isso é utilizado depois de formado. Isso contribui muito!” (EB35)

Além de elevar a qualidade da formação inicial de professores nos cursos de licenciatura, promovendo a integração entre educação superior e educação básica, proporcionando ao acadêmico estar presente desde a sua formação no ambiente no qual [sic] será seu ambiente de trabalho. (EB29)

O Pibid ajuda a formar professores com uma percepção diferente a respeito do contexto escolar e das nuances que podem existir dentro de uma sala de aula. A participação no Pibid é essencial para uma melhor compreensão do que é o ensino na educação básica e como podemos atuar com o intuito de fazê-lo cada vez mais eficaz. $(E B 24)$

O contato com os alunos, pois fornece (ao futuro professor), as primeiras experiências quanto ao diálogo com os estudantes e ao desenvolvimento de métodos de ensino (quando for auxiliar a compreensão do conteúdo). Tudo isso faz o acadêmico entender que é necessário estar sempre buscando, sempre estudando. (EB2)

A principal contribuição do programa é que ele permite que os acadêmicos planejem atividades e depois discutam o que deu certo e o que não deu e reorganizem. Assim, cada um pode refletir sobre o que está fazendo e ir acertando. (EB30)

O Pibid proporciona um contato maior dos graduandos com a escola, alunos e comunidade escolar que será seu meio de trabalho posterior à formatura. Também é importante porque nesse programa os 'pibidianos' trabalham em equipe, isso ajuda a desenvolver técnicas e métodos de trabalho para uma futura aplicação em suas vidas profissionais. (EB8) 
Incentivo: é inegável que a bolsa é um grande incentivo para se permanecer na graduação e no futuro na profissão. Experiência: estar em sala de aula não mais como aluno lhe dá uma grande bagagem, fora a experiência compartilhada dos professores titulares. (EB14)

De acordo com os resultados evidenciados neste grupo, os ex-bolsistas entendem que os objetivos do programa estão sendo alcançados, pois suas respostas vão ao encontro das ideias de Nóvoa (2009, p. 75), quando afirma que:

[...] la formacióm de professores ganaría mucho si se organizasse, preferentemente, en torno de situaciones concretas de fracaso escolar, de problemas escolares o de programas de acción educativa. Y si inspirasse junto a los futuros professores la miesma obstinación y perseverancia que los médico revelan en la búsqueda de las mejores soluciones para cada caso.

Assim, a iniciativa de inserir os futuros docentes no seu futuro ambiente de trabalho proporciona o desenvolvimento dos saberes docentes necessários para o exercício da profissão. E tais saberes, segundo Tardif (2014), devem sempre ser pensados como diretamente relacionados ao trabalho dos professores na escola e na sala de aula. Isto é, o saber docente não pode ser pensado como algo separado da prática. E como demonstrou esta pesquisa, não se trata de abandonar o estudo dos aspectos teóricos e conceituais durante a formação dos professores, mas de ter como base, ao longo desse período, a referência de casos concretos do cotidiano escolar, sua dinâmica, seus anseios e dificuldades.

\section{Considerações finais}

A formação de professores para atuar na educação básica brasileira tem sido elemento de discussões e preocupações, porém, essas inquietações não foram suficientes para consolidar uma formação adequada, e tampouco proporcionaram uma justa valorização da carreira dos profissionais da educação. Tal fato originou uma gigantesca e histórica carência de professores preparados para atender às demandas atuais, oriundas de um mundo complexo e em constante transformação.

Frente a esse contexto, o Pibid/Física tem se mostrado uma alternativa capaz de ressignificar a formação inicial de professores, por meio da tão almejada articulação entre teoria e prática. Para isso, busca inserir os estudantes no seu futuro local de atuação profissional desde o início de sua formação, em atividades didático-pedagógicas, para as quais o conhecimento é construído, na sua forma e no seu conteúdo, por um processo de interação radical entre o sujeito e o meio.

De acordo com a investigação aqui apresentada, os objetivos do programa estão sendo alcançados, uma vez que os resultados evidenciam que a maioria dos ex-bolsistas do programa estão ministrando aulas e buscando a qualificação pedagógica em cursos de graduação 
e/ou pós-graduação. Percebe-se, ainda, que os participantes atribuem a escolha profissional e a opção por continuarem se qualificando à participação no programa. Tais resultados, que corroboram os de estudos anteriores (MORYAMA; PASSOS; ARRUDA, 2013; PIRATELO; PASSOS; ARRUDA, 2014; DARROZ; WANNMACHER, 2015a, 2015b, 2016), levam à conclusão de que o Pibid/Física pode incentivar a formação de docentes em nível superior para a educação básica e elevar a qualidade da formação inicial de professores nos cursos de licenciatura.

No que diz respeito à experiência adquirida no desenvolvimento das atividades do programa, evidencia-se que os participantes utilizam muitas metodologias e estratégias elaboradas e implementadas no Pibid/Física nas aulas que ministram atualmente. Constata-se, também, que os ex-bolsistas acreditam que o programa os auxiliou na escolha de temas de investigação para cursos de pós-graduação e no desenvolvimento de pesquisas. Tudo isso indica que inserir os licenciandos no cotidiano escolar no decorrer de sua graduação lhes proporciona situações para a aquisição de um rol de metodologias e estratégias didáticas e metodológicas que vão balizar sua prática pedagógica.

Os resultados ainda demonstram que, na opinião dos participantes da pesquisa, o programa desenvolve ações que contribuem significativamente para a formação docente. Dentre os elementos destacados, estão a oportunidade de estudar a partir de casos concretos do ambiente escolar, de refletir sobre a profissão docente, de testar metodologias e estratégias de ensino, de ter contato desde cedo com o ambiente de sua futura profissão, de poder trocar experiências com professores e colegas, de receber uma bolsa de estudos - podendo se dedicar exclusivamente às tarefas do curso de licenciatura - e, principalmente, de ter a oportunidade de relacionar a teoria estudada nos bancos escolares com a realidade cotidiana de uma escola.

Por tudo isso, e no contexto da pesquisa, conclui-se que o Pibid tem se constituído um programa inovador no campo da formação de professores de Física no Brasil, podendo elevar substancialmente a qualidade das ações acadêmicas nos cursos de licenciatura. Para tanto, as disciplinas dos cursos de formação devem configurar-se como espaço diferenciado de articulação entre o conhecimento específico e o conhecimento pedagógico, adotando o ambiente escolar como local central de formação docente e de metodologias que se assemelhem àquelas desenvolvidas no Pibid/Física.

\section{Referências}

BARDIN, L. Análise de conteúdo. Lisboa: Edições 70, 2011.

BORGES, J. F. M. et al. Resistores não ôhmicos à base de água. Caderno Brasileiro de Ensino de Física, Florianópolis, v. 23, n. 2, p. 267-276, 2006. 
BRASIL. Ministério da Educação. Secretaria da Educação Média e Tecnológica. Parâmetros Curriculares Nacionais $+(\mathbf{P C N}+)$ - Ciências da Natureza e suas Tecnologias. Brasília: MEC, 2002.

. Decreto $\mathrm{n}^{\circ} 7.219$, de 24 de junho de 2010. Dispõe sobre o Programa Institucional de Bolsa de Iniciação à Docência - Pibid e dá outras providências. Diário Oficial da União, n. 120, seção 1, p. 4-5, 2010.

Ministério da Educação. Capes. Programa Institucional de Bolsa de Iniciação à Docência. Regulamento do Programa Institucional de Bolsa de Iniciação à Docência. Brasília: Capes, 2013. Disponível em:

<https://www.capes.gov.br/images/stories/download/legislacao/Portaria_096_18jul13_Aprov aRegulamentoPIBID.pdf>. Acesso em: 19 set. 2016.

DARROZ, L. M.; PERÉZ, C. A. S. Princípio de Arquimedes: uma atividade experimental. A Física na Escola, v. 12, n. 2, p. 28-31, 2011.

DARROZ, L. M.; WANNMACHER, C. M. D. Aprendizagem docente no âmbito do Pibid/Física: a visão dos bolsistas de iniciação à docência. Ensaio Pesquisa em Educação em Ciências, v. 17, n. 3, p. 727-748, 2015a.

Aprendizagem docente proporcionada pela participação no Pibid/Física: a visão dos coordenadores de área. Revista Brasileira de Ensino de Ciências e Tecnologia, v. 8, n. 4 , p. $221-241,2015$ b.

.; __ Aprendizagem docente no âmbito do Programa Institucional de Bolsa de Iniciação à Docência - Física: o que dizem os supervisores. Imagens da Educação, v. 6, n. 1, p. 38-49, 2016.

DICK, A. P.; DIESEL, D.; HORN, D. Pibid: uma política pública para potencializar a articulação entre teoria, prática e reflexão docente". Caderno Pedagógico, v. 12, n. 2, p. 138-148. 2015.

FEJOLO, T. B.; ARRUDA, S. M.; PASSOS, M. M. Aprendizagem científica informal no Pibid: identificando e interpretando os focos. Caderno Brasileiro de Ensino de Física, v. 30, n. 3, p. 628-649, 2013.

JOHAN, C. S. et al. Promovendo a aprendizagem sobre fungos por meio de atividades práticas. Ciência e Natura, v. 36, ed. especial II, p. 798-805, 2014.

LAKATOS, E. M.; MARCONI, M. A. Fundamentos de Metodologia Científica. 7. ed. São Paulo: Atlas, 2010.

MARMITT, D. J.; BASSANI, V. L.; DIESEL, A. Aspectos da interação entre bolsistas do Pibid com alunos de ensino médio em oficina sobre trabalhos acadêmicos. Caderno Pedagógico, v. 10, n. 1, p. 97-108, 2013. 
MORYAMA, N.; PASSOS, M. M.; ARRUDA, S. M. Aprendizagem da docência no PibidBiologia. Alexandria - Revista de Educação em Ciência e Tecnologia, v. 6, n. 3, p. 191210, 2013.

NEITZEL, A. A.; FERREIRA, V. S.; COSTA, D. Os impactos do Pibid nas licenciaturas na Educação Básica. Conjectura: Filosofia e Educação, v. 18, n. especial, p. 98-121, 2013.

NEVES, C. M. C. A Capes e a formação de professores para a educação básica. Revista Brasileira de Pós-Graduação, Brasília, supl. 2, v. 8, n. 16, p. 353-373, 2012.

NÓVOA, A. Para una formación de profesores construida dentro de la profesión. Revista de Educación, v. 350, p. 203-218, 2009.

PIRATELO, M. V. M.; PASSOS, M. M.; ARRUDA, S. M. Um estudo a respeito das evidências de aprendizado docente no PIBID da Licenciatura em Física. Caderno Brasileiro de Ensino de Física, v. 31, n. 3, p. 493-517, 2014.

ROSA, C. T. W. et al. Concepções epistemológicas dos docentes dos anos iniciais: um estudo envolvendo as atividades experimentais no Ensino de Ciências (Física). Ensino de Ciências e Tecnologia em Revista, v. 3, p. 30-48, 2013.

ROSA, C. T. W.; ROSA, A. B.; GIACOMELLI, A. C. Interdisciplinaridade e o contexto escolar: investigações a partir de uma atividade lúdica de interesse dos estudantes. Ciência e Natura, v. 38, n. 1, p. 535-543, 2016.

SANTOS, C. A. B. dos; CURI, E. A formação dos professores que ensinam física no ensino médio. Ciência \& Educação, v. 18, n. 4, p. 837-849, 2012.

SOUZA, F. S.; GUALBERTO, L. N. C.; SOUZA, V. B. Matemática cruzada: proporcionando saberes por meio do jogo e da resolução de problemas. Boletim do LABEM, ano 6, n. 10, 2015.

SOUZA, R. M. Q. O Programa institucional de bolsas de iniciação à docência numa universidade da grande São Paulo: depoimentos, contradições e reflexões preliminares. Acta Scientiarum. Education, v. 36, n. 2, p. 309-316, 2014.

TARDIF, M. Saberes docentes e formação profissional. 14. ed. Petrópolis, RJ: Vozes, 2014. 